Cite this: I. Mater. Chem A, 2013, 1 15509

Received 15th July 2013

Accepted 11th October 2013

DOI: $10.1039 / c 3 t a 12744 c$

www.rsc.org/MaterialsA

\title{
Oxygen reduction and methanol oxidation behaviour of SiC based Pt nanocatalysts for proton exchange membrane fuel cells $\uparrow$
}

\author{
Rajnish Dhiman, ${ }^{* a}$ Serban N. Stamatin, ${ }^{a}$ Shuang M. Andersen, ${ }^{a}$ Per Morgen ${ }^{b}$ \\ and Eivind M. Skou ${ }^{a}$
}

Research with proton exchange membrane fuel cells has demonstrated their potential as important providers of clean energy. The commercialization of this type of fuel cell needs a breakthrough in the electrocatalyst technology to reduce the relatively large amount of noble metal platinum used with the present carbon based substrates. We have recently examined suitably sized silicon carbide (SiC) particles as catalyst supports for fuel cells based on the stable chemical and mechanical properties of this material. In the present study, we have continued our work with studies of the oxygen reduction and methanol oxidation reactions of $\mathrm{SiC}$ supported catalysts and measured them against commercially available carbon based catalysts. The deconvolution of the hydrogen desorption signals in CV cycles shows a higher contribution of Pt (110) and Pt (111) peaks compared to Pt (100) for SiC based supports than for carbon based commercial catalysts, when $\mathrm{HClO}_{4}$ is used as an electrolyte. The Pt (110) and Pt (111) facets are shown to have higher electrochemical activities than Pt (100) facets. To the best of our knowledge, methanol oxidation studies and the comparison of peak deconvolutions of the $\mathrm{H}$ desorption region in CV cyclic studies are reported here for the first time for SiC based catalysts. The reaction kinetics for the oxygen reduction and for methanol oxidation with $\mathrm{Pt} / \mathrm{SiC}$ are observed to be similar to the carbon based catalysts. The SiC based catalyst shows a higher specific surface activity than BASF (Pt/C) for methanol oxidation and oxygen reduction while the mass activity values are comparable.

\section{Introduction}

Fuel cells are becoming the current focus of energy research due to their high efficiency and for being environmentally friendly. The state of the art fuel cells use platinum as a catalyst which contributes around $30-45 \%$ to the total cost, ${ }^{1}$ thus making this technology very expensive. A catalyst in the form of Pt nanoparticles is uniformly dispersed over the support to enhance the catalytic surface area and reduce the amount of catalyst needed. Several different alloys of $\mathrm{Pt}$ have been investigated with different metals such as $\mathrm{Pd}, \mathrm{Ni}, \mathrm{Co}, \mathrm{Cr}, \mathrm{Sn}, \mathrm{Ru}^{1,2}$ etc. as a possible choice for enhancing the catalytic activity and reducing the cost

\footnotetext{
${ }^{a}$ Department of Chemical Engineering, Biotechnology and Environmental Technology, University of Southern Denmark (SDU), Niels Bohrs Alle 1, DK-5230 Odense M, Denmark

${ }^{b}$ Department of Physics, Chemistry and Pharmacy, University of Southern Denmark (SDU), Campusvej 55, DK-5230 Odense M, Denmark.E-mail: rdhiman@sdu.dk; Fax: +45-6615 8760; Tel: +45-6550 23603

$\dagger$ Electronic supplementary information (ESI) available: Basic theory of oxygen reduction reaction, detailed information about the instruments used for characterization, detailed XPS analysis of Pt/SiC-SMS and additional images of Tafel plots and cyclic voltammograms are given in the ESI along with some additional CVs of the catalysts. See DOI: $10.1039 / \mathrm{c} 3$ ta12744c
}

of the fuel cells. Apart from catalysts, a catalyst support is also an important avenue of research in order to commercialize the fuel cells. Carbon black is the standard catalyst support used in PEMFCs to obtain an optimized catalytic activity at a reasonable cost. ${ }^{3,4}$ Generally, a good catalyst support material should have chemical inertness, high mechanical strength, high thermal stability, good electrical conductivity and high surface area. Other forms of carbon, which were proven to be more corrosion resistant, ${ }^{5}$ are graphitized carbon black, carbon nanofibers, carbon nanotubes $^{5-7}$ and other graphene related materials. ${ }^{8}$ These materials can be produced with high conductivity and specific surface areas. However, the carbon black supports are susceptible to electrochemical oxidation especially at the fuel cell cathode. ${ }^{9,10}$ The carbon corrosion leads to the migration and agglomeration of catalyst particles. ${ }^{9}$ This process results in the decrease of electrochemical surface area (ESA) and it affects the performance of the PEMFCs. Thus some alternative support materials are highly desired to enhance the stability of the catalysts. $^{\mathbf{1 1}}$

Different ceramic materials have been investigated for applications as catalyst supports in fuel cells. Titanium based materials such as $\mathrm{TiB}_{2}{ }^{12}{ }^{12} \mathrm{TiO}_{2}{ }^{13}$ and $\mathrm{TiN}$ nanoparticles ${ }^{14}$ have been investigated and reported to show good electrochemical 
activity. Nikiforov et al. ${ }^{15}$ studied the electrochemical activity of $\mathrm{IrO}_{2}$ supported on SiC-Si composites and they observed an increased activity of the catalyst. $\mathrm{Lv}$ et $a{ }^{4}{ }^{4}$ studied the electrocatalytic activity of $\mathrm{Pt} / \mathrm{SiC}$ and $\mathrm{Pt} / \mathrm{SiC} / \mathrm{C}$ and they found good electrocatalytic performance for $\mathrm{Pt} / \mathrm{SiC} / \mathrm{C}$. In our recent work, ${ }^{16}$ we also observed a slightly higher ESA for Pt/SiC catalysts in comparison with commercially used carbon black based catalysts (BASF), where Pt nanoparticles are deposited over the SiC nanocrystals by the polyol method, using $\mathrm{K}_{2} \mathrm{PtCl}_{4}$ as the metal precursor unlike in the work by Lv et al.

Reduction of Pt-loadings will help to commercialize the fuel cell technology. ${ }^{\mathbf{1 7}}$ Pt-loadings have successfully been decreased from $0.2-0.4 \mathrm{mg}_{\mathrm{Pt}} \mathrm{cm}^{-2}$ to $0.05 \mathrm{mg}_{\mathrm{Pt}} \mathrm{cm}^{-2}$ for the anode electrode $^{18}$ because of the large activity of $\mathrm{Pt}$ towards the $\mathrm{H}_{2}$ oxidation reactions. The reaction kinetics of the oxygen reduction reaction (ORR) involve multi-electron reactions along with several elementary steps, ${ }^{1}$ thus requiring higher overpotentials. This complex ORR kinetics along with poor activity of $\mathrm{Pt}$ for ORR pose hurdles for reduction of the Pt-loading $\left(0.4 \mathrm{mg}_{\mathrm{Pt}}\right.$ $\mathrm{cm}^{-2}$ ) on cathodes. ${ }^{18}$ Thus it makes for the ORR to be among the most studied electrocatalytic reactions. It is important to study the ORR of $\mathrm{Pt}$ based electrocatalysts on different catalyst supports. Also, the methanol oxidation reaction (MOR) is a slow process in comparison with the hydrogen oxidation reactions (at least three to four orders of magnitude slower). ${ }^{19}$ MOR involves the transfer of six electrons to the electrode for the complete oxidation to carbon dioxide. Several intermediates are formed during the methanol oxidation such as CO, formic acid, formaldehyde ${ }^{20}$ etc. Some species such as CO irreversibly adsorb on the surface of the electrocatalyst thus decreasing the surface area available for adsorbing $\mathrm{CH}_{3} \mathrm{OH}$ and severely poison the $\mathrm{Pt}$ for the rest of the reaction. This also leads to a decrease in the rate of oxidation. Thus, new electrocatalysts are required to inhibit the poisoning and to increase the rate of oxidation.

$\mathrm{SiC}$ has certain unique properties such as good chemical and mechanical properties, thermal stability, and acid corrosion resistance, ${ }^{\mathbf{1 6}}$ which perfectly fits with the requirements for a good support material. In the present work, we have studied the oxygen reduction reaction and methanol oxidation behavior of SiC based supports.

\section{Experimental methods}

\section{Materials and sample preparation}

The Pt/SiC electrocatalysts are prepared by depositing platinum on SiC substrates by using the polyol method. The method of Pt deposition on SiC materials has been reported previously. ${ }^{16}$ The SiC materials in different forms and shapes are used as substrates. The details of the three different SiC materials are given in Table 1. Apart from these $\mathrm{Pt} / \mathrm{SiC}$ materials, a commercially available $\mathrm{Pt} / \mathrm{C}(20 \mathrm{wt} \% \mathrm{Pt})$ catalyst (BASF, LOT \# H0020626) has also been tested for comparison with electrochemical behavior of $\mathrm{Pt} / \mathrm{SiC}(20 \mathrm{wt} \% \mathrm{Pt})$. The catalyst, $\mathrm{Pt} / \mathrm{C}$ catalyst (BASF, LOT \# H0020626), is mentioned as BASF in the whole manuscript.

The aqueous acid electrolyte solutions were prepared from perchloric acid (70\% Fluka TraceSelect ${ }^{\circledR}$, for trace analysis) and ultrapure Milli-Q ${ }^{\circledR}$ (Millipore, MA USA) water with a resistivity of not less than $18 \mathrm{M} \Omega \mathrm{cm}$. ORR kinetics were investigated using a rotating disk electrode (RDE). SiC supported platinum nanocatalyst samples were deposited on the RDE surface. The catalysts of around $2-3 \mathrm{mg}$ were mixed in a sufficient amount of Milli- $Q^{\circledR}$ water and sonicated for around $30 \mathrm{~min}$. The amount of water was decided upon according to the targeted Pt loading on the RDE surface. The final catalyst loading was around $120 \mu \mathrm{g}_{\mathrm{Pt}} \mathrm{cm}^{-2}$ for SiC based electrodes, while $30 \mu \mathrm{g}_{\mathrm{Pt}} \mathrm{cm}^{-2}$ was used for BASF. In order to achieve full coverage of the RDE for ORR, we optimized a loading of $120 \mu \mathrm{g}_{\mathrm{Pt}} \mathrm{cm}^{-2}$ for Pt/SiC due to the larger density and smaller BET surface area of SiC in comparison with the active carbon supports. A drop of $50 \mu \mathrm{L}$ suspension was put over the mirror polished glassy carbon (GC) and left to dry under an IR lamp.

\section{Electrochemical methods and setup}

The electrochemical CV measurements were performed using a Zahner IM6eX electrochemical workstation (Zahner-Electric GmBH \& Co. KG, Germany) controlled by a Thales 1.48 . The RDE setup used is from Pine Research Instruments and it consists of an AFMSRXE modulated speed rotator and a tip (E5 $\mathrm{RDE}$ ), and also a $5.0 \mathrm{~mm}$ diameter (geometric surface area of $0.1964 \mathrm{~cm}^{2}$ ) mirror polished glassy carbon electrode surface.

Table 1 Details of the SiC materials tested in the present work

\begin{tabular}{|c|c|c|c|}
\hline Sample name (type) & Particle size & Specific surface area $(\mathrm{SSA}) / \mathrm{m}^{2} \mathrm{~g}^{-1}$ & Synthesis route \\
\hline SiC-NS (nanoporous SiC powder) & $25-35 \mathrm{~nm}$ & Calculated $^{a}$ as $54-75 \mathrm{~m}^{2} \mathrm{~g}^{-1}$ & $\begin{array}{l}\text { Synthesized by the reaction of } \\
\text { carbon black with } \mathrm{SiO} \text { vapors }{ }^{16,21} \text { at } \\
\text { a temperature } 1450{ }^{\circ} \mathrm{C}\end{array}$ \\
\hline SiC-SPR (SiC nanocrystals) & $50-150 \mathrm{~nm}$ & $\begin{array}{l}\text { Calculated }^{a} \text { as } 18.7 \mathrm{~m}^{2} \mathrm{~g}^{-1} \text { using } \\
100 \mathrm{~nm} \text { as the diameter }\end{array}$ & $\begin{array}{l}\text { Synthesized by the solid phase } \\
\text { reaction of silicon with carbon black } \\
\text { at a temperature of } 1525^{\circ} \mathrm{C}^{16}\end{array}$ \\
\hline SiC-SMS (microporous SiC powder) & $1-10 \mu \mathrm{m}$ & $\begin{array}{l}\text { BET surface area measured to be in } \\
\text { the range of } 11.82-21.2 \mathrm{~m}^{2} \mathrm{~g}^{21}\end{array}$ & $\begin{array}{l}\text { Synthesized by the reaction of } \\
\text { carbon with SiO vapors, where the } \\
\text { carbon is obtained by the } \\
\text { carburization of wood }\end{array}$ \\
\hline
\end{tabular}

${ }^{a}$ The particles have been assumed as spheres, thus the specific surface area has been calculated by dividing the surface area by the mass of particles. 
The RDE along with the catalyst dispersed onto the GC surface was used as the working electrode in a two compartment, three electrode set up. A reversible hydrogen electrode (RHE) from Gaskatel GmbH, Germany, was used as the reference electrode (RE), while a platinum wire of $0.3 \mathrm{~mm}$ thickness wound to 40 windings constituting approximately $3 \mathrm{~mm}$ diameter, sealed in a glass tube with a ceramic frit, was used as the counter electrode (CE). All the measurements were performed at a temperature of $25{ }^{\circ} \mathrm{C}$, which was kept constant with the help of a thermostat. All potentials listed are with respect to RHE.

ORR studies were conducted in a two compartment, three electrode setup filled with $200 \mathrm{ml}$ of $0.5 \mathrm{M} \mathrm{HClO}_{4}$. The background was collected at $0.05 \mathrm{~V} \mathrm{~s}^{-1}$ from 0.05 to $1.3 \mathrm{~V}$ in an $\mathrm{Ar}$ saturated electrolyte. ORR was recorded in an $\mathrm{O}_{2}$ saturated electrolyte at $0.05 \mathrm{~V} \mathrm{~s}^{-1}$ for 400, 900, 1600 and $2500 \mathrm{rpm}$. Both

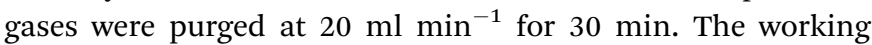
electrode was cleaned from 0.01 to $1.6 \mathrm{~V}$ until a stable signal was obtained. In order to measure the kinetic current the measurements recorded in Ar were subtracted from the ones in $\mathrm{O}_{2}$.

MOR was studied in a total volume of $200 \mathrm{ml}$ containing $0.25 \mathrm{M} \mathrm{HClO}_{4}$ and $0.25 \mathrm{M}$ methanol. Ar was purged for $30 \mathrm{~min}$ at

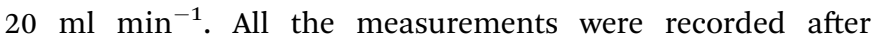
subsequent cleaning of the working electrode by cycling until a stable $\mathrm{CV}$ is obtained. MOR was recorded in the potential range of 0 to $1.4 \mathrm{~V}$, at a scan rate of $10 \mathrm{mV} \mathrm{s}^{-1}$. The investigated catalyst was drop coated on a $0.12 \mathrm{~cm}^{2} \mathrm{Au}$ electrode which was connected by a gold wire as the working electrode. All the data were processed by using OriginPro $8.5^{\circledR}$ (Originlab, USA).

\section{Calculations}

Electrochemical surface area. The electrochemical surface area (ESA) is the surface area of the catalyst particles available for the electrode reaction. The ESA is obtained by measuring the charges involved in the hydrogen desorption/adsorption regions of the cyclic voltammogram $(\mathrm{CV})$, recorded in an oxygen free electrolyte. The corresponding charges are calculated by integrating the hydrogen desorption region, and dividing it by the scan speed $(v)$. The contribution due to the double layer charging is subtracted during the calculation. The calculation of the ESA is carried out by the following equation: ${ }^{16,22}$

$$
\mathrm{ESA}=\frac{Q_{\mathrm{H}}}{C},
$$

where ESA is the electrochemical surface area $\left[\mathrm{cm}^{2}\right], Q_{\mathrm{H}}$ is the average charge [C] for hydrogen adsorption and desorption while $C$ is a constant $\left(C=210 \mu \mathrm{C} \mathrm{cm}^{-2}\right)$.

Oxygen reduction reactions. The catalytic activity for ORR is evaluated by calculating the surface activity (SA) by the following equation.

$$
\mathrm{SA}=\frac{I_{\mathrm{k}}}{\mathrm{ESA}}
$$

where $I_{\mathrm{k}}$ is the kinetic current and ESA is the electrochemical surface area. The current, $I$, for a rotating disc electrode is related to the value of the diffusion limited current, $I_{\mathrm{L}}$, and kinetic current, $I_{\mathrm{k}}, .^{23,24}$ The kinetic current can be calculated by the Koutecky-Levich equation (which is the reciprocal of the intercept along the $y$-axis, if $i^{-1}$ is plotted against $\omega^{-1 / 2}$ ) as shown below:

$$
\frac{1}{i}=\frac{1}{i_{\mathrm{k}}}+\frac{1}{B \omega^{\frac{1}{2}}},
$$

where $\omega$ is the angular velocity in $\operatorname{rad~s}^{-1}, i$ and $i_{\mathrm{k}}$ are the specific currents obtained by normalizing $I_{\mathrm{k}}$ to ESA and $B$ is a constant with its value given by eqn (4).

$$
B=0.62 n F A c_{\mathrm{o}} D_{\mathrm{o}}^{\frac{3}{2}} v^{\frac{-1}{6}}
$$

In eqn (4), $n$ is the number of electrons transferred, $F$ is the Faraday constant (96 $485.53 \mathrm{Cmol}^{-1}$ ), $A$ is the area of the electrode used, $c_{\mathrm{o}}$ and $D_{\mathrm{o}}$ are respectively the concentration and diffusion coefficient of oxygen in the bulk electrolyte, and $v$ is the kinematic viscosity of the liquid phase.

Methanol oxidation reactions. The cyclic voltammogram (CV) of MOR consists of a peak in the forward scan and another peak in the reverse scan, both arising due to the oxidation of methanol and/or intermediates. ${ }^{25}$ The determination of activity of the MOR is based upon the amount of charge transferred during the oxidation. The catalytic activity for methanol oxidation is assessed by the surface specific activity (SSA) and is calculated with the following equation, ${ }^{26-28}$

$$
\mathrm{SSA}=\frac{Q_{\mathrm{M}}}{\mathrm{ESA}}
$$

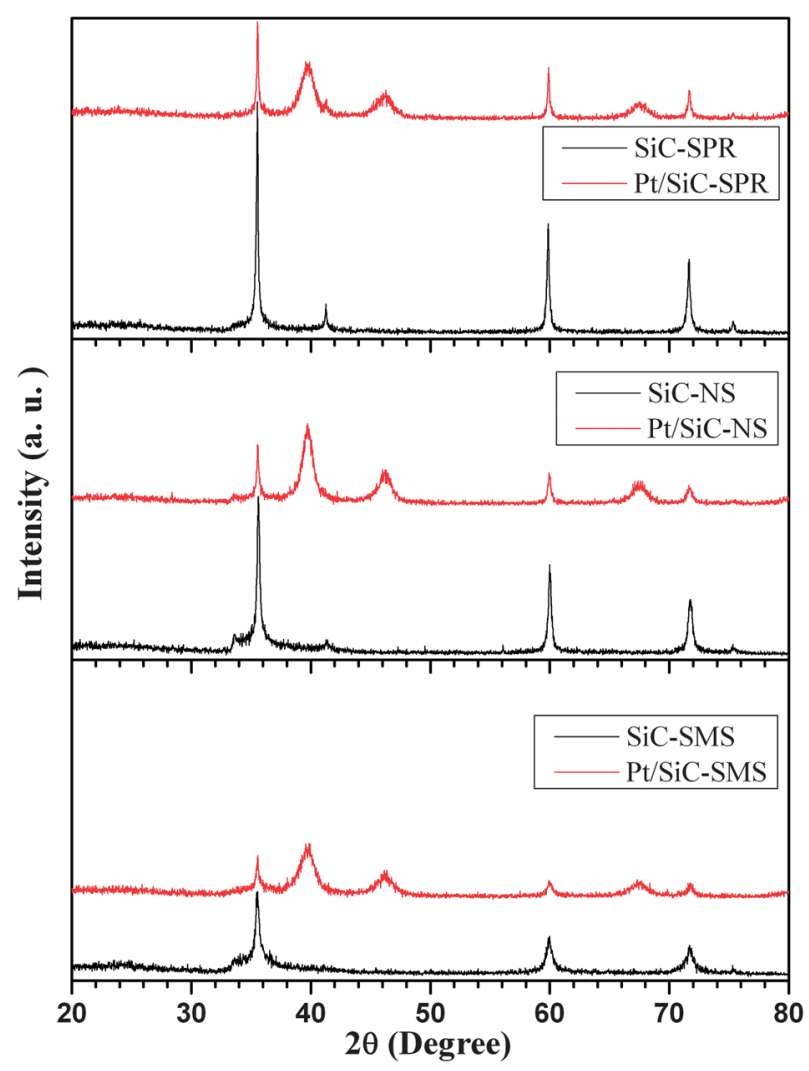

Fig. 1 XRD patterns of SiC nanocrystals and the Pt/SiC electrocatalysts. (a) nanocrystals synthesized by solid phase reaction, (b) nanoporous SiC synthesized by reaction with silicon monoxide and (c) microporous $\mathrm{SiC}$ powder. 
where $Q_{M}$ is the charge required for the oxidation of methanol (which is calculated by the integration in the methanol oxidation region of the $\mathrm{CV}$ ).

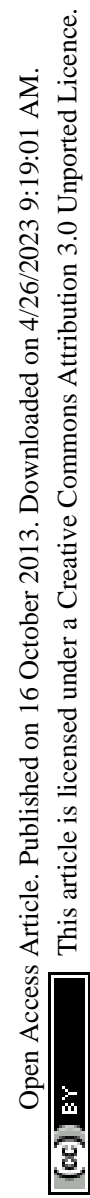
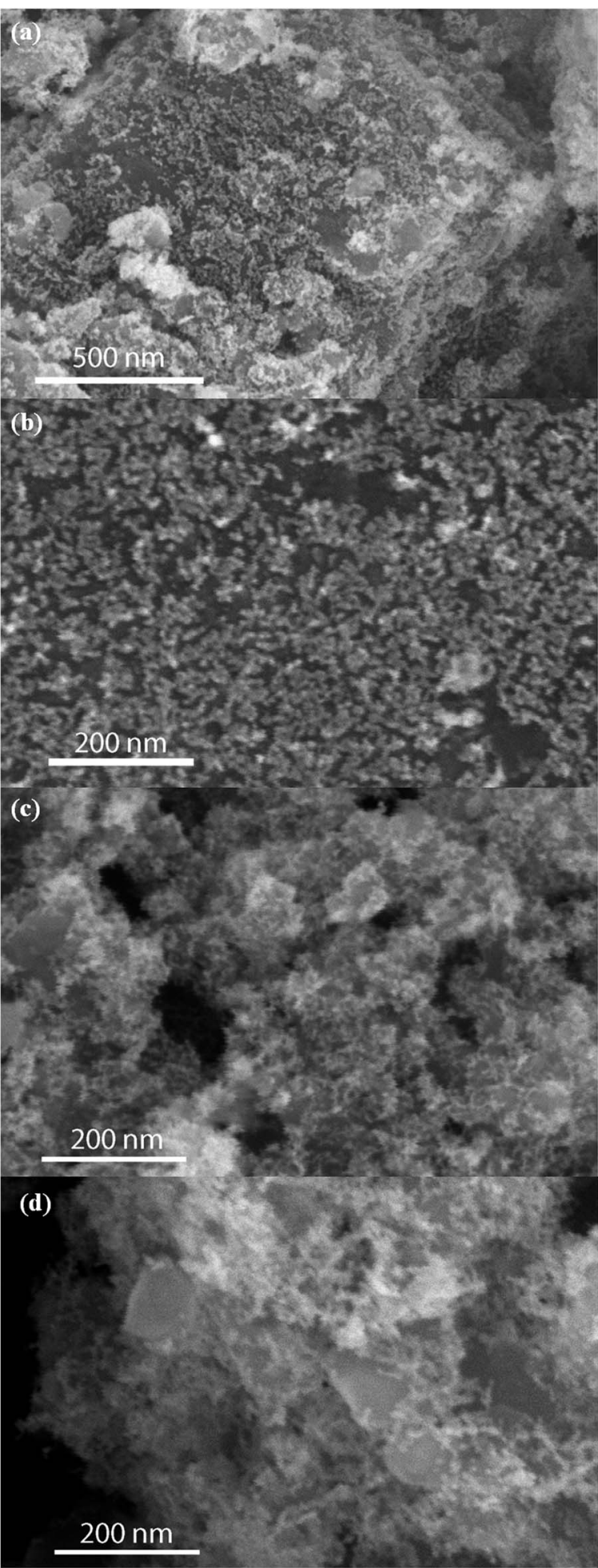

Fig. 2 SEM images of the Pt/SiC electrocatalysts at different magnifications. (a) and (b) show SEM images of Pt nanoparticles deposited over SiC-SMS (Pt/SiCSMS), (c) and (d) show images of Pt catalyst on SiC-NS (Pt/SiC-NS) and SiC-SPR (Pt/SiC-SPR) respectively.

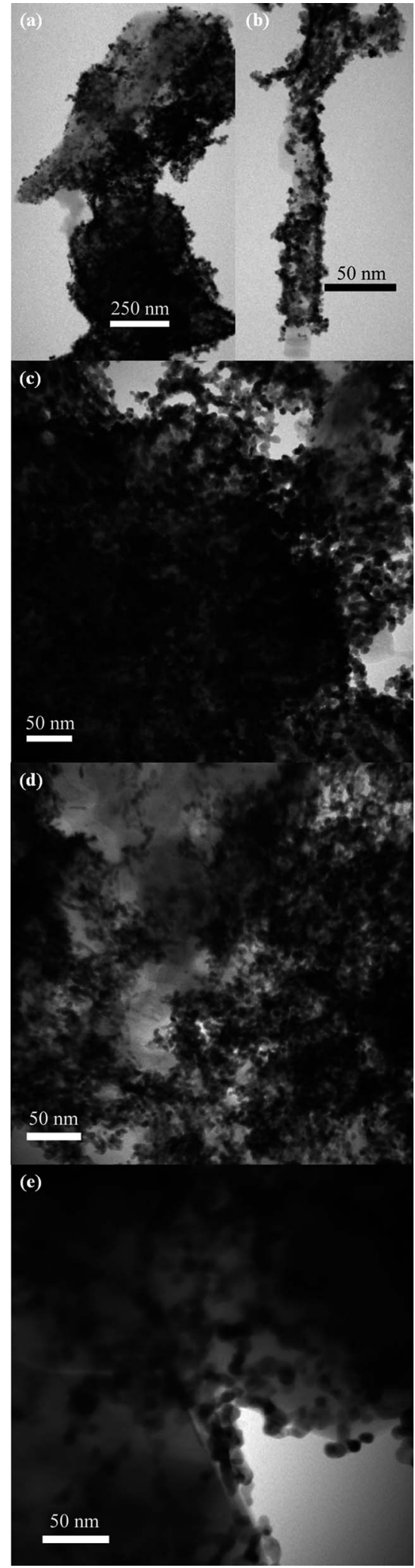

Fig. 3 TEM images of the electrocatalysts $\mathrm{Pt} / \mathrm{SiC}$ at different magnifications. (a), (b) and (c) are TEM images of Pt/SiC-SMS at different magnifications and different regions, (d) and (e) are images of Pt/SiC-NS and Pt/SiC-SPR respectively. 


\section{Results and discussion}

\section{Catalyst characterization}

The XRD patterns of the different $\mathrm{Pt} / \mathrm{SiC}$ catalysts shown in Fig. 1 display the peaks corresponding to SiC and Pt. The peaks at $2 \theta=35.6^{\circ}, 41.3^{\circ}, 60.0^{\circ}, 71.7^{\circ}$ and $75.4^{\circ}$ correspond to diffraction from SiC (111), (200), (220), (311) and (222) planes respectively, while the peaks at $39.7^{\circ}, 46.2^{\circ}$ and $67.5^{\circ}$ appear due to the diffraction from (111), (200), and (220) planes of Pt. The average Pt crystallite size was estimated by the Scherrer formula using the full width at half maximum (FWHM) of the peak at $39.7^{\circ}$. The calculation of the Pt crystallite size using the
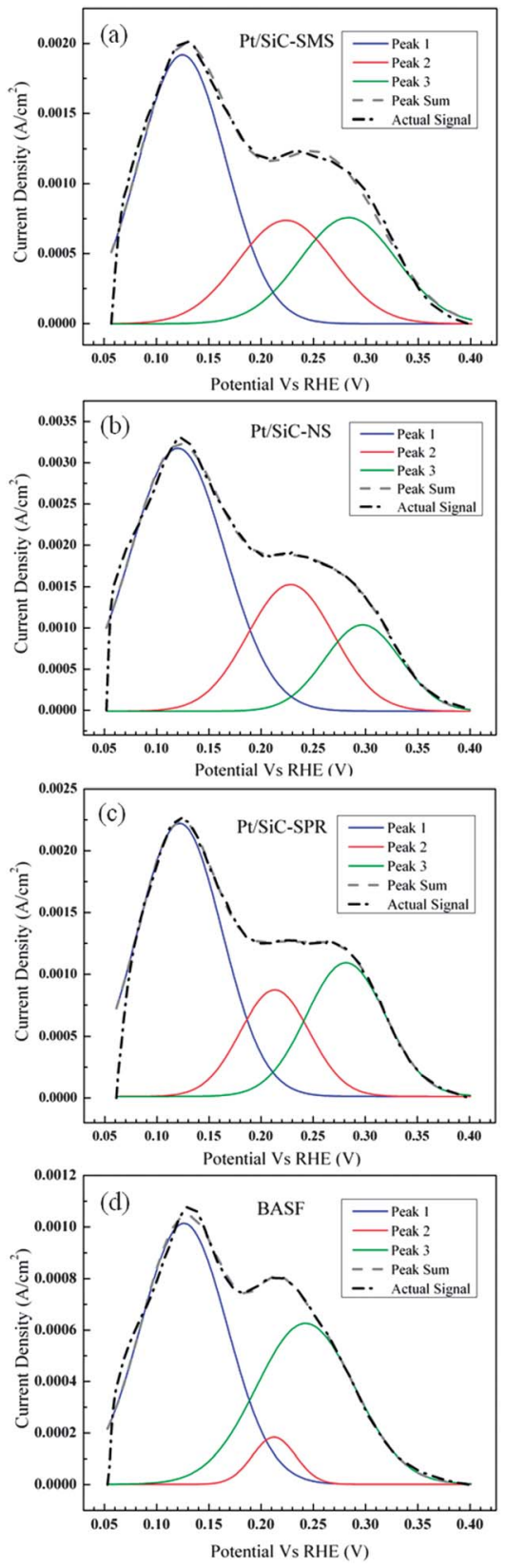

Fig. 4 Peak deconvolution of the cyclic voltammograms of different samples in the $\mathrm{H}$ desorption region. The Pt loading on electrodes is $30 \mu \mathrm{g} \mathrm{cm}^{-2}$ for BASF and $120 \mu \mathrm{g} \mathrm{cm}^{-2}$ for SiC based catalyst samples.
Scherrer formula gives values of $3.7 \mathrm{~nm}, 5 \mathrm{~nm}$ and $5.8 \mathrm{~nm}$ for SiC-NS (nano-porous), SiC-SPR (nanocrystals) and SiC-SMS (micro-porous) respectively.

Fig. 2 and 3 show respectively the SEM and TEM images of $\mathrm{Pt} / \mathrm{SiC}$ catalysts synthesized upon different SiC based supports. Pt nanoparticles appear light grey to white in contrast to the darker SiC particles in SEM images while Pt nanoparticles appear darker in TEM images compared to SiC. The SiC substrates have been masked by the Pt particles. The size of the Pt nanoparticles in the samples SiC-SMS and SiC-SPR is in the range of 3-8 $\mathrm{nm}$ while for SiC-NS the size range is $3-5 \mathrm{~nm}$. The calculation of the average size of samples (based upon TEM images) gives the average values of $3.9 \pm 2.3,5.5 \pm 2.6$ and $7.0 \pm$ $2.0 \mathrm{~nm}$ for SiC-NS, SiC-SMS and SiC-SPR respectively. The histograms of particle size distribution are given in Fig. S2, ESI. $\uparrow$ The comparison of the respective SEM and TEM images (especially $\mathrm{Pt} / \mathrm{SiC}-\mathrm{SMS}$ with $\mathrm{Pt} / \mathrm{SiC}-\mathrm{NS}$ and $\mathrm{Pt} / \mathrm{SiC}-\mathrm{SPR}$ ) indicates that the $\mathrm{Pt}$ is distributed evenly over the supports irrespective of the differences in the size of support particles.

The detailed characterization of Pt/SiC-NS and Pt/SiC-SPR was reported previously. ${ }^{16}$ The XPS analysis of Pt/SiC-SMS is given in the ESI. $\dagger$

\section{Electrochemical characterization}

Peak deconvolution in the hydrogen desorption curves. The cyclic voltammograms of $\mathrm{Pt} / \mathrm{SiC}$ consist of different signals, which provide information about different electrochemical processes such as hydrogen adsorption/desorption, platinum oxide formation and stripping and double layer charging. The adsorption and desorption regions are generally composed of two distinct peaks corresponding to $\mathrm{Pt}$ (100) (at a potential of $0.28 \mathrm{~V} v s$. RHE) and to Pt (110) and Pt (111) facets (at a potential of $0.12 \mathrm{~V} v s$. RHE) of the Pt crystal. A third anodic peak has also

Table 2 Ratio of Pt (110 and111) peak to Pt (100) peak (based upon area integrations of Fig. 4)

\begin{tabular}{ll} 
Sample name & Ratio of Pt(110 and 111) to Pt(100) peaks \\
\hline Pt/SiC-NS & 3.54 \\
Pt/SiC-SMS & 2.20 \\
Pt/SiC-SPR & 2.02 \\
BASF & 1.37
\end{tabular}

Table 3 Surface activity (SA) and mass activity (MA) of the SiC based catalysts in comparison with commercially available BASF

\begin{tabular}{lllll}
\hline Sample name & $\begin{array}{l}\text { Pt loading } \\
(\%)\end{array}$ & $\begin{array}{l}\mathrm{ECSA}^{a} \\
\left(\mathrm{~m}^{2} \mathrm{~g}^{-1}\right)\end{array}$ & $\begin{array}{l}\mathrm{SA} \\
\left.(\mathrm{mA} \mathrm{cm})^{-2}\right)\end{array}$ & $\begin{array}{l}\mathrm{MA}^{b} \\
\left(\mathrm{~A} \mathrm{mg}^{-1}\right)\end{array}$ \\
\hline BASF & 20 & 62.2 & 0.29 & 0.18 \\
Pt/SiC-SMS & 20 & 38.6 & 0.25 & 0.12 \\
Pt/SiC-NS & 20 & 49.7 & 0.36 & 0.18 \\
Pt/SiC-SPR & 20 & 39.2 & 0.28 & 0.14
\end{tabular}

${ }^{a}$ ECSA has been calculated by dividing ESA by the Pt electrode loading. ${ }^{b}$ MA has been calculated by dividing the kinetic current by Pt electrode loading. 
been observed to occur between these two peaks because of the oxidation of the sub-surface hydrogen. ${ }^{29}$

The sequence of electrochemical activity in $\mathrm{HClO}_{4}$ shows the following trend Pt (110) > Pt (111) > Pt (100). ${ }^{30}$ Fig. 4 shows the peak deconvolution of the CVs of different samples in the $\mathrm{H}$ desorption region. Deconvolution of the desorption region curve is done by fitting the peaks as Gaussians using OriginPro $8.5^{\circledR}$. Table 2 shows the ratio of the Pt (110 and 111) peaks to the
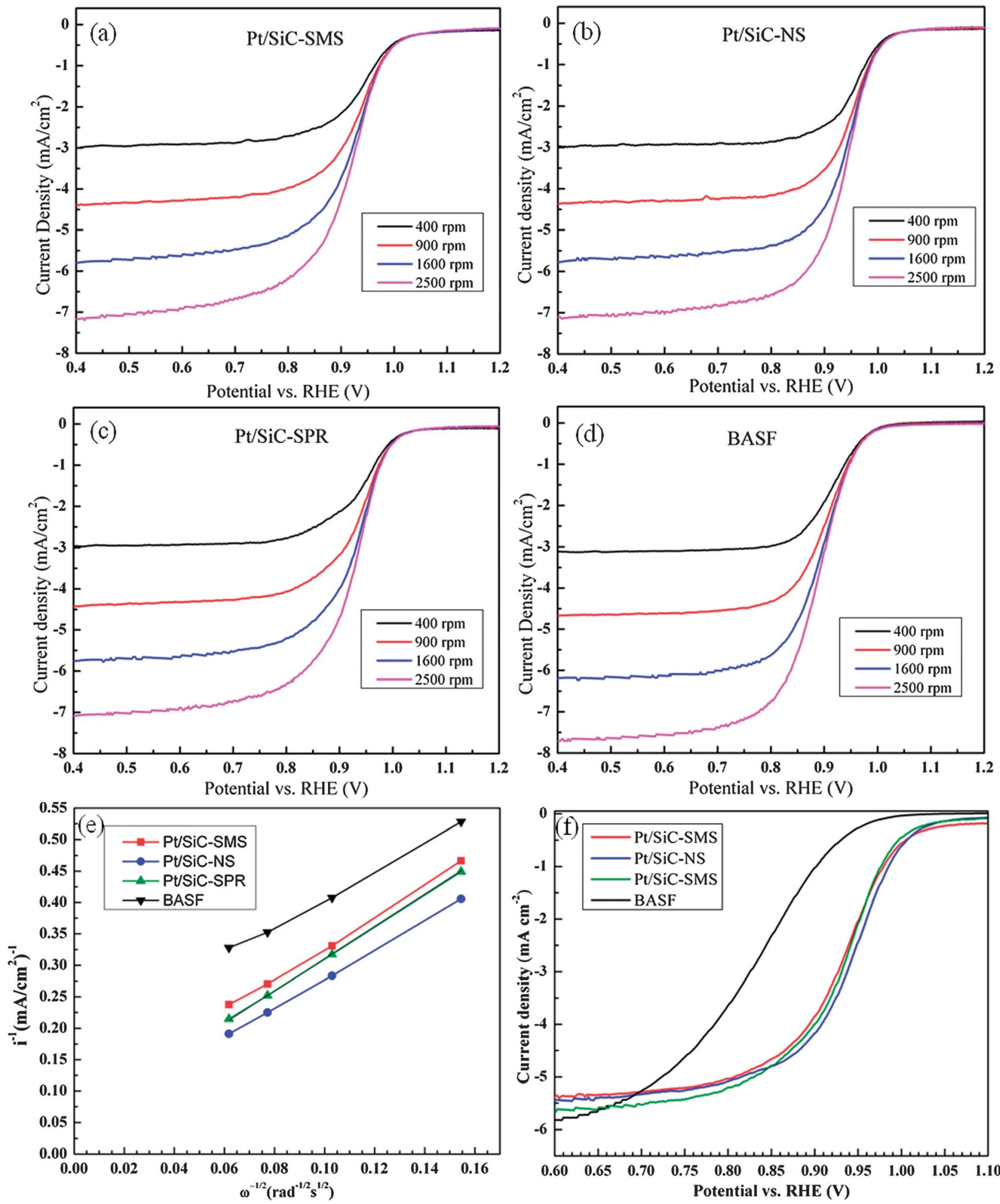

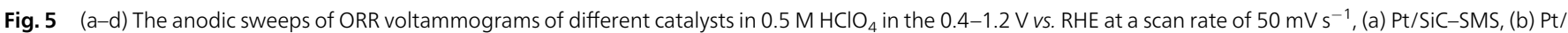

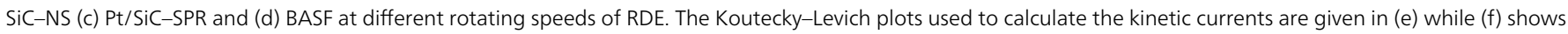
the linear sweep voltammograms for all electrocatalysts in $\mathrm{O}_{2}$ saturated $0.5 \mathrm{M} \mathrm{HClO}_{4} ; 0.05 \mathrm{~V} \mathrm{~s}^{-1}, 1600 \mathrm{rpm}$. 
Pt (100) peak. The ratios of the peaks have been calculated from the $\mathrm{H}$ desorption curves for the different samples (shown in Fig. 4). It is clear from Fig. 4 and Table 2 that SiC based samples have higher contribution from the Pt (110) and Pt (111) facets in comparison with the platinized carbon based commercial sample BASF in the $\mathrm{HClO}_{4}$ electrolyte.

The ECSA values for different $\mathrm{SiC}$ based catalysts in comparison with commercial BASF are shown in Table 3 (also reported in our earlier work ${ }^{\mathbf{1 6}}$ ). The ECSA values do not reflect the Pt particle sizes. It is well known that on $\mathrm{Pt} / \mathrm{C}$ (Vulcan), some $\mathrm{Pt}$ particles are not accessible for electrochemical reactions. We believe that the above mentioned inconsistency is caused by a similar effect.

Oxygen reduction reaction. Fig. 5 gives the anodic sweeps of the ORR voltammograms $(\mathrm{a}-\mathrm{d})$ at different rotating speeds of RDE, Koutecky-Levich (e) and linear sweep voltammograms (f) for three $\mathrm{SiC}$ based catalysts and one carbon based catalyst (BASF). The ordinate shows the current densities (the current divided by the geometric area of the electrode). The hydrogen adsorption/desorption polarization curves are subtracted from the ORR curves. The ORR sweep starts from the higher potential and undergoes a sharp inclination around $0.8 \mathrm{~V} v s$. RHE which is due to oxygen stripping from Pt. The reduction current increases until it reaches the limiting current (the maximum attainable current). Below $0.2 \mathrm{~V}$ (vs. RHE), the current is decreased because of the blockage of Pt sites due to hydrogen adsorption.

Kinetic currents have been calculated using eqn (3) by extrapolating the reciprocal current (shown in Fig. 5(e)) to the zero on $\omega^{-1 / 2}$ axes (infinite rotation); the intercept at the $y$-axis is the kinetic current while the slope of the extrapolated line is used to find the number of electrons transferred per oxygen molecule on the catalyst. All the SiC based samples show similar or higher SA than BASF while the mass activity (MA, see Table 3) of $\mathrm{Pt} / \mathrm{SiC}-\mathrm{NS}$ is the same as the BASF and less for the other two samples. Similar values of MA and SA were reported for $20 \mathrm{wt}_{\mathrm{Pt}} \% \mathrm{Pt} / \mathrm{C}$ by Gasteiger et al. ${ }^{18}$ The number of electrons transferred at $0.9 \mathrm{~V}$ ( $v s$. RHE) as calculated for all tested samples

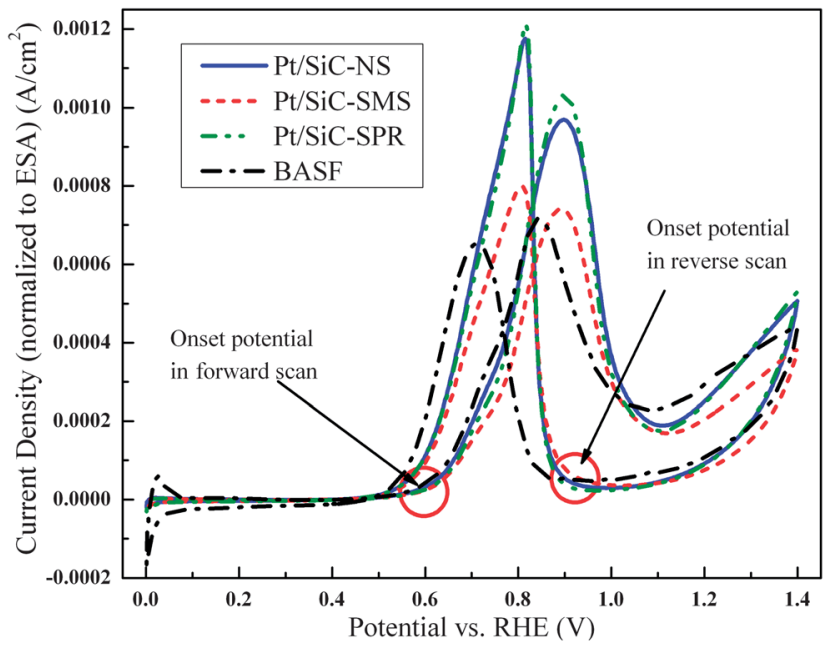

Fig. 6 Cyclic voltammograms of different Pt/SiC and BASF catalysts in $0.5 \mathrm{M}$ $\mathrm{CH}_{3} \mathrm{OH}$ at $10 \mathrm{mV} \mathrm{s}^{-1}$.
Table 4 Mass specific activity and surface specific activity of the SiC based catalysts in comparison with commercially available Pt/C (BASF) for methanol oxidation reaction

\begin{tabular}{lll}
$\begin{array}{l}\text { Sample } \\
\text { name }\end{array}$ & $\begin{array}{l}\text { Mass specific activity (MSA) } \\
\left(\mathrm{C} \mathrm{mg}_{\mathrm{Pt}}^{-1}\right)\end{array}$ & $\begin{array}{l}\text { Surface specific activity }^{a}(\mathrm{SSA}) \\
\left(\mathrm{mC} \mathrm{cm}^{-2}\right)\end{array}$ \\
\hline SiC-NS & 6.80 & 16.9 \\
SiC-SPR & 4.82 & 16.9 \\
SiC-SMS & 4.50 & 12.5 \\
BASF & 6.96 & 11.1
\end{tabular}

${ }^{a}$ SSA has been calculated by dividing $Q_{\mathrm{M}}$ (the charge required for the oxidation of methanol) by ERS.

are 3.7, 3.7, 3.8 and 3.9 for BASF, Pt/SiC-SMS, Pt/SiC-NS and $\mathrm{Pt} / \mathrm{SiC}-\mathrm{SPR}$ respectively. Thus it confirms the $4 \mathrm{e}^{-}$pathway for the ORR for all the catalysts. Fig. 5(f) and S2† show a significant shift in the ORR onset for $\mathrm{Pt} / \mathrm{SiC}$ compared to the commercial $\mathrm{Pt} / \mathrm{C}$ (BASF). The Tafel plots for all the tested samples are shown in Fig. S4 (ESI). $\dagger$ As a whole, the slopes of the SiC based catalysts are similar to the BASF, indicating similar reaction kinetics for ORR.

Methanol oxidation reactions (MOR). The cyclic voltammogram curves for methanol oxidation (MOR) of three SiC based catalysts and one carbon based commercial catalyst (BASF) are shown in Fig. 6. The methanol oxidation cyclic voltammograms shown in the present work are the first ever reported for SiC based Pt electrocatalysts. Apart from the slight changes in the shapes and positions, the CVs of SiC based catalysts look similar to the voltammograms of carbon based catalysts as compared here (for BASF) and also reported in the literature. ${ }^{20,31,32}$ The methanol oxidation starts around the same potential for all the tested samples (including BASF). The onset potential for MOR is around $0.6 \mathrm{~V} v s$. RHE. The shape of the MOR peak (from 0.6-1.1 V vs. RHE) for all the catalysts is similar with a small difference in BASF where it is slightly tilted towards the lower potential. The peak in the backward scan for SiC based catalysts shows more "sharpness" in comparison with Vulcan based BASF. The current density shown in Fig. 6 is obtained by dividing the current by the electrochemical real surface area (ERS) (the product of ESA and the amount of Pt used on the electrode). Table 4 gives the mass specific activity and surface specific activity of the different samples. All the SiC based catalysts have significantly higher SSA than the BASF, while SiC-NS and BASF have comparable values of MSA. The higher value of MSA for BASF is because of the higher value of ESA due to the better catalyst utilization. Thus, from Table 4, we can conclude that based upon SSA, SiC based catalysts are better than the commercially available catalyst (BASF) for methanol oxidation reactions.

\section{Conclusions}

In the present study, we have investigated the electrochemical behavior of SiC based catalysts and compared it with the commercially available Vulcan based catalyst BASF. We have studied the oxygen reduction reaction and methanol oxidation 
along with the deconvolution of $\mathrm{H}$ desorption peaks of the $\mathrm{CV}$ curves. The comparison of the deconvoluted $\mathrm{H}$ desorption peaks of $\mathrm{Pt} / \mathrm{SiC}$ to $\mathrm{Pt} / \mathrm{C}$ is being reported for the first time. We observed higher contribution of the $\mathrm{Pt}(110$ and 111) signal than $\mathrm{Pt}(100)$ in the case of different SiC based catalysts in comparison with BASF. The electrochemical activity is higher for the $\mathrm{Pt}(110)$ and $\mathrm{Pt}(111)$ than for $\mathrm{Pt}(100)$ in $\mathrm{HClO}_{4}$. The surface activity of the SiC based catalysts is found to be higher for one sample while comparable for others and the mass activity is found to be comparable for one while smaller for others. Overall, the reaction kinetics for all the tested samples including BASF are found to be similar. The methanol oxidation behaviour of $\mathrm{SiC}$ based catalysts has also been reported for the first time and the results obtained are similar to the ORR results. The surface specific activity of SiC based catalysts is higher than the BASF while the mass specific activity of one SiC based sample is comparable to BASF and slightly smaller for others. Thus, the overall conclusion of the electrochemical studies shows SiC based catalysts as better than or equally competent to BASF.

\section{Acknowledgements}

The authors are grateful to the Danish Ministry for Research and Innovation for providing a grant to R. Dhiman, 2104-050073 through its program for Sustainable Energy and The Environment. They are further grateful to the Danish PSO project CATBOOSTER 2011-1-10669. The authors are thankful to T. Warner, P. B. Hansen, D. Kyrping, and T. Sørensen at SDU for advice and technical support.

\section{Notes and references}

1 A. Rabis, P. Rodriguez and T. J. Schmidt, ACS Catal., 2012, 2, 864-890.

2 N. M. Markovic, T. J. Schmidt, V. Stamenkovic and P. N. Ross, Fuel Cells, 2001, 1, 105-116.

3 T. R. Ralph and M. P. Hogarth, Platinum Met. Rev., 2002, 46, 3-14.

4 H. Lv, S. Mu, N. Cheng and M. Pan, Appl. Catal., B, 2010, 100, 190-196.

5 J. Y. Cheon, C. Ahn, D. J. You, C. Pak, S. H. Hur, J. Kim and S. H. Joo, J. Mater. Chem. A, 2013, 1, 1270.

6 M. J. Larsen and E. M. Skou, J. Power Sources, 2012, 202, 3546.

7 S. M. Andersen, M. Borghei, P. Lund, Y.-R. Elina, A. Pasanen, E. Kauppinen, V. Ruiz, P. Kauranen and E. M. Skou, Solid State Ionics, 2013, 231, 94-101.

8 E. Antolini, Appl. Catal., B, 2009, 88, 1-24.

9 N. Cheng, S. Mu, M. Pan and P. P. Edwards, Electrochem. Commun., 2009, 11, 1610-1614.
10 L. M. Roen, C. H. Paik and T. D. Jarvi, Electrochem. Solid-State Lett., 2004, 7, A19-A22.

11 D. A. Stevens and J. R. Dahn, Carbon, 2005, 43, 179-188.

12 S. Yin, S. Mu, H. Lv, N. Cheng, M. Pan and Z. Fu, Appl. Catal., $B, 2010,93,233-240$.

13 S. Huang, P. Ganesan, S. Park and B. N. Popov, J. Am. Chem. Soc., 2009, 131, 13898-13899.

14 B. Avasarala, T. Murray, W. Li and P. Haldar, J. Mater. Chem., 2009, 19, 1803-1805.

15 A. V. Nikiforov, T. A. L. Garcia, I. M. Petrushina, E. Christensen and N. J. Bjerrum, Int. J. Hydrogen Energy, 2011, 36, 5797-5805.

16 R. Dhiman, E. Johnson, E. M. Skou, P. Morgen and S. M. Andersen, J. Mater. Chem. A, 2013, 1, 6030.

17 I. E. L. Stephens, A. S. Bondarenko, U. Grønbjerg, J. Rossmeisl and I. Chorkendorff, Energy Environ. Sci., 2012, 5, 6744 .

18 H. A. Gasteiger, S. S. Kocha, B. Sompalli and F. T. Wagner, Appl. Catal., B, 2005, 56, 9-35.

19 A. S. Aricò, S. Srinivasan and V. Antonucci, Fuel Cells, 2001, 1, 133-161.

20 R. Chetty, W. Xia, S. Kundu, M. Bron, T. Reinecke, W. Schuhmann and M. Muhler, Langmuir, 2009, 25, 38533860 .

21 R. Dhiman, V. Petrunin, K. Rana and P. Morgen, Ceram. Int., 2011, 37, 3281-3289.

22 M. Søgaard, M. Odgaard and E. M. Skou, Solid State Ionics, 2001, 145, 31-35.

23 T. J. Schmidt, H. A. Gasteiger, G. D. Stab, P. M. Urban, D. M. Kolb and R. J. Behm, J. Electrochem.Soc., 1998, 145, 2354-2358.

24 U. A. Paulus, T. J. Schmidt, H. A. Gasteiger and R. J. Behm, J. Electroanal. Chem., 2001, 495, 134-145.

25 J. Munk, P. A. Christensen, A. Hamnett and E. Skou, J. Electroanal. Chem., 1996, 401, 215-222.

26 C. Paoletti, A. Cemmi, L. Giorgi, R. Giorgi, L. Pilloni, E. Serra and M. Pasquali, J. Power Sources, 2008, 183, 84-91.

27 A. B. Kashyout, A. B. A. A. Nassr, L. Giorgi and T. Maiyalagan, Int. J. Electrochem. Sci., 2011, 6, 379-393.

28 D. M. Gattia, M. V. Antisari, L. Giorgi, R. Marazzi, E. Piscopiello, A. Montone, S. Bellitto, S. Licoccia and E. Traversa, J. Power Sources, 2009, 194, 243-251.

29 T. Frelink, W. Visscher and J. A. R. van Veen, Electrochim. Acta, 1995, 40, 545-549.

30 J. C. Meier, C. Galeano, I. Katsounaros, A. A. Topalov, A. Kostka, F. Schu and K. J. J. Mayrhofer, ACS Catal., 2012, 2, 832-843.

31 C. Zhou, H. Wang, F. Peng, J. Liang, H. Yu and J. Yang, Langmuir, 2009, 25, 7711-7717.

32 L. Giorgi, T. D. Makris, R. Giorgi, N. Lisi and E. Salernitano, Sens. Actuators, B, 2007, 126, 144-152. 